\title{
ANTIMICROBIAL RESISTANCEAMONG INTENSIVE CARE UNIT PATIENTS IN A TERTIARY CARE HOSPITAL OF BANGLADESH
}

\author{
HUMAYRA JESMIN ${ }^{1}$, HAM NAZMUL AHASAN ${ }^{2}$, MD. ASADUZZAMAN ${ }^{3}$, AKM MONWARUL ISLAM $^{4}$
}

\begin{abstract}
:
Background: Antimicrobial resistance is a growing concern specially among the critically ill patients who are often treated by multiple antibiotics. But, the data regarding the pattern of antimicrobial resistance in this population are often insufficient.

Objective: To observe the pattern of antimicrobial resistance among the patients admitted into the intensive care unit (ICU).

Methodology: This prospective observational study was carried out in the ICU of a tertiary care hospital of Bangladesh over 6 months. Samples of blood, urine, tracheal aspirate, wound swab and pus were obtained from the patients, cultured and analyzed.

Results: Among 100 subjects, the most common primary diagnoses were aspiration pneumonia (29\%) and urinary tract infection (UTI) (24\%). Out of 315 samples, microorganisms were isolated from 125 samples (39.68\%). The most common sample yielding positive culture was tracheal aspirate (67.2\%), and the most frequently isolated microorganisms were Pseudomonas spp. (35\%), Escherichia coli (28\%), Acinetobacterspp. (24\%) andKlebsiellaspp. (18\%). Acinetobacterspp., Pseudomonasspp. and Klebsiellaspp.were the commonest resistant organisms. Overall prevalence of resistance to antibiotics were: ceftriaxone $72 \%$, ceftazidime $78.4 \%$, ciprofloxacin $81.6 \%$, gentamicin $84 \%$, meropenem 49.6\% andnetilmicin 39.2\%. Meropenem was the most sensitive antibiotic against Klebsiellaspp.(66.67\%) but Acinetobacterspp.was still resistant to meropenem and amikacin but sensitive to cotrimoxazole (66.67\%). Multidrug resistant Pseudomonas, Acinetobacter and, Klebsiella species were found; piperacillin-tazobactam combination showed $<40 \%$ resistance against them. No single antibiotic showed good efficacy against Acinetobacterspp.
\end{abstract}

Conclusion: The prevalence of antibiotic resistance is high among the ICU patients, and the majority of the isolated organisms are resistant to conventional antibiotics.

Keywords: Antimicrobial resistance, microorganism, antibiotic, intensive care unit.

Received: 11 October, 2020

Accepted: 25 December, 2020

DOI: https://doi.org/10.3329/bjm.v32i1.51088

\section{Introduction}

The intensive care unit (ICU) is often called the epicenter of infection due to its extremely vulnerable population. The risk of infection increasesbecause of multiple procedures and use of invasive devices e.g., intubation, mechanical ventilation, vascular access, central venous lines distorting the integrity of protective barriers. In addition, several drugs are often administered, which predispose to infections. For example sedatives, muscle relaxants precipitate pneumonia by reducing cough and swallow reflexes or stress ulcer prophylaxis predispose to infection by distorting the normal nonpathogenic bacterial flora. ${ }^{1}$ Consequently, the ICU population has one of

1. Junior Consultant, Medicine, National Institute of Kidney Diseases \& Urology (NIKDU), Dhaka, Bangladesh.

2. Professor, Department of Medicine, Popular Medical College, Dhaka, Bangladesh.

3. Post-Graduate Fellow, BangabandhuSheikh Mujib Medical University, Dhaka, Bangladesh.

4. Associate Professor, Department of Cardiology, National Institute of Cardiovascular Diseases (NICVD), Dhaka, Bangladesh.

Address of correspondence: Dr. HumayraJesmin, Junior Consultant, Department of Nephrology, NIKDU, Sher e Bangla Nagar, Dhaka 1207, Bangladesh. Email: dr.jesmin.humayra@gmail.com

Bangladesh J Medicine 2021; 32 : 5-11 
the highest occurrence rates of nosocomial infections $(20-30 \% \text { of all ICU-admissions })^{2,3}$, leading to an enormous impact on morbidity, hospital costs, and often, survival. ${ }^{4-6}$ According to the Extended Prevalence of Infection in Intensive Care (EPIC) II 1-day prospective point-prevalence study in 1,265 participating ICUs in 75 countries worldwide, 51\% of the 12,796 patients were considered infected, although no subdivision was made for hospitalacquired infections. ${ }^{7}$ The patients in the ICU have a 5-to7-fold higher risk of nosocomial infection compared with the other patients due to underlying illness, suppressed immune systems and frequent use of invasive devices, exposure to broad spectrum antibiotics and the colonization of resistant microorganisms. Suspected infection may be pneumonia, meningitis, intra-abdominal infection, urinary tract infection and catheter-related infections. ${ }^{8}$ Along with the problem of nosocomial infection, the ongoing emergence of resistance in the community and hospital is considered a major threat for public health. Due to the specific risk profile of its residents, the ICU is deemed the epicenter of resistance development, as well as, has even been described as a factory for creating, disseminating, and amplifying antimicrobial resistance. ${ }^{9}$ Both infection and multidrug resistance (MDR) result in a considerable clinical and economic burden. As such, the presence of MDR boosts the deleterious impact of nosocomial infection. ${ }^{10}$ Due to the specific risk of infection, the additional cost of MDR in hospitalized patients with infections has been estimated at $\$ 6,000$ to $\$ 30,000$ per patient. ${ }^{11}$ This burden of resistance, however, is probably more due to higher rate of inappropriate empiric antimicrobial treatment associated with infections caused by MDR pathogens than with the virulence of particular MDR strains. ${ }^{12}$ In a study in an Indian ICU, the most common organisms were Acinetobacter spp., Escherichia coli, Klebsiellaspp., Pseudomonas aeruginosa, Staphylococcus aureus, and Streptococcus pyogenes. ${ }^{13}$ But in a European ICU, Staphylococcus aureus was found as the most frequently isolated organism (30.1\%), followed by Pseudomonas aeruginosa (28.7\%), Coagulase-negative Staphylococcus (19.1\%) and Yeast $(17.1 \%)^{14}$. In almost all cases, there is a need to initiate empirical antimicrobial treatment before obtaining the microbial culture results, but the situation is further complicated during the past decades, a shift in the MDR dilemma has been noted from gram-positive to gram-negative bacteria, especially due to the scarceness of new antimicrobial agents activeagainst resistant gramnegative microorganisms ${ }^{15}$. Among gram-positive organisms, the Staphylococcusaureus, and vancomycin-resistant enterococci are of great concern ${ }^{15,16}$. In gram-negative bacteria, the resistance is mainly due to the rapid increase of extendedspectrum beta-lactamases (ESBLs) in Klebsiella pneumonia, Escherichia coli, and Proteus mirabilis; high level third-generation cephalosporin beta-lactamase resistance among Enterobacter spp. AndCitrobacter spp., and MDR in Pseudomonas aeruginosa, Acinetobacterspp., and Stenotrophomonas maltophilia $^{16}$. Several other types of infections become more difficult to treat like anaerobicClostridium difficile, and fungal species. Infections with resistant strains of microorganisms in the ICUs lead to increased mortality and cost. ${ }^{17}$ All these major reports indicate the need for obtaining data on resistant strains in the ICU along with the susceptibility pattern, to help in revising antibiotic policy and guiding clinicians for the better management of patients. Prevalent flora and antimicrobial resistance pattern may vary from region to region depending upon the predominant antibiotic use in that locality. Standard treatment guidelines of different microbes in ICUs are not sufficient for the purpose. Therefore, the present study was designed to determine the pattern of antimicrobial resistance among the ICU patients.

\section{Materials and methods Methodology}

This observational study was carried out inthe ICU of Dhaka Medical College Hospital, Dhaka, Bangladesh in 2015 over a period of 6 months. The objective was to determine the antibiotic resistance pattern among the adult ICU patients. The patients of either sex ageing 18 years or more suffering from various medical conditions and being treated with broad-spectrum antibiotics were included. Samples of blood, urine, sputum/tracheal aspirate and pus/wound swabs were collected from consecutive patients. The collected samples were cultured in standard culture media for isolation of potential pathogens following standard methods. For each isolate, antibiotic susceptibility was performed by disc diffusion method. Isolates showing sensitivity to all antibiotics, isolates from repeat culture of previously recruited patients and isolate identified as commensals, colonization or contaminants were excluded. Isolates with intermediate susceptibility were considered resistant.

The study protocol was approved by the Bangladesh College of Physicians and Surgeons (BCPS), and the Ethical Review Committee of Dhaka Medical College.Informed written consent was obtained from the patients or their attendants.

For the study, data were collected in a pre-designed structured data collection form, analyzed using SPSS for windows version 16.0. 


\section{Results}

From the 100 ICU patients, 125 specimens were obtained. Among the collected specimens, 66\% were from males and 34\% from females. Twenty-one percent of the patients were within the 61-70 years of age group and $17 \%$ aged $>70$ years. The most common primary diagnoses were aspiration pneumonia (29\%), andurinary tract infection (UTI) (24\%), respectively(Table1). The most common locations for infection were tracheal aspirate (67.2\%), urine (16\%), and blood (10.4\%) (Table2). The most frequent microorganisms isolated were Pseudomonas spp. (35\%), Escherichia coli (28\%), Acinetobacter spp. (24\%), andKlebsiella spp. (18\%) which were mostly found in sample from tracheal aspirate (Table 3).

Table 4, 5, and 6 show the sensitivity of different microorganisms to common antibiotics. In Table7, out of 125 samples, $72 \%$ were resistant to ceftriaxone and $78.4 \%$ were resistant to ceftazidime. These organisms were mostly Pseudomonas spp., Escherichia coli, Acinetobacter spp. and Klebsiella spp.Klebsiella spp. were resistant toceftriaxone $(83.33 \%)$, ceftazidime $(44.45 \%)$, amikacin $(72.22 \%)$, gentamicin $(72.28 \%)$ and quinolones (82.22-83.33\%) (Table- 4, 5, 6). Acinetobacter spp.were resistant toceftriaxone (58.44\%), ceftazidime $(79.17 \%)$, meropenem $(75 \%)$, amikacin (66.67\%), gentamicin $(75 \%)$ and quinolones (79.17-92.67\%) (Table 4, 5, 6). Pseudomonas spp. were resistant toceftriaxone (77.24\%), ceftazidime (94.29\%), amikacin $(68.57 \%)$, gentamicin $(74.29 \%)$, meropenem $(74.29 \%)$ and quinolones (60-77.15\%) (Table 4, 5, 6).Meropenem was the most sensitive antibiotic against Klebsiella spp. (66.67\%) but Acinetobacter spp. were still resistant to meropenem and amikacin but sensitive to cotrimoxazole (66.67\%) (Table 6). Table 4 and 5 show
Escherichia coli was mostly sensitive to netilmicin (71.43\%) and meropenem (50\%).

Table-I

Primary diagnosis of the ICU patients. $(N=100)$

\begin{tabular}{lcc}
\hline Primary diagnosis & Frequency & Percentage \\
\hline Aspiration pneumonia & 29 & 29.0 \\
UTI & 24 & 24.0 \\
Septicemia & 12 & 12.0 \\
Meningitis & 12 & 12.0 \\
Pneumonia & 10 & 10.0 \\
COPD with respiratory failure & 8 & 8.0 \\
Surgical wound infection & 5 & 5.0 \\
\hline Total & 100 & 100.0 \\
\hline
\end{tabular}

Table-II

Sample profile and rate

\begin{tabular}{|c|c|c|c|}
\hline \multirow[t]{2}{*}{ Sample } & \multirow{2}{*}{$\begin{array}{l}\text { otal number } \\
\text { of samples }\end{array}$} & \multicolumn{2}{|c|}{ Growth of organism } \\
\hline & & Number & Percentage \\
\hline Blood & 100 & 13 & 10.4 \\
\hline Urine & 100 & 20 & 16 \\
\hline Tracheal secretion & 93 & 84 & 67.2 \\
\hline Wound swabPus & 1210 & 53 & 42.4 \\
\hline Total & 315 & 125 & 39.68 \\
\hline
\end{tabular}

Table 2 : Sample profile and rate of positive culture from different samples $(\mathrm{N}=315)$

Table-III

Frequency of different microorganisms from various samples $(N=125)$

\begin{tabular}{|c|c|c|c|c|c|c|}
\hline Microorganism & Blood & Trachealaspirate & Urine & Wound swab & Pus & Total \\
\hline Pseudomonas & 8 & 21 & 6 & 0 & 0 & 35 \\
\hline E.coli & 1 & 15 & 7 & 3 & 2 & 28 \\
\hline Acinetobacter & 0 & 22 & 1 & 1 & 0 & 24 \\
\hline Klebsiella & 0 & 16 & 2 & 0 & 0 & 18 \\
\hline Staph aureus & 4 & 6 & 1 & 0 & 0 & 11 \\
\hline Streptococcus pneumoniae & 0 & 2 & 0 & 0 & 0 & 2 \\
\hline Proteus mirabilis & 0 & 2 & 0 & 0 & 0 & 2 \\
\hline Morganellamorganii & 0 & 0 & 2 & 0 & 0 & 2 \\
\hline Citrobacter & 0 & 0 & 0 & 1 & 1 & 2 \\
\hline Enterococcus & 0 & 0 & 1 & 0 & 0 & 1 \\
\hline Total & 13 & 84 & 20 & 5 & 3 & 125 \\
\hline
\end{tabular}


Table-IV

Distribution of microorganisms according to susceptibility to penicillins, cephalosporins and meropenem (N=125)

\begin{tabular}{lcccccccc}
\hline Microorganisms & $\begin{array}{c}\text { Piperacillin+tazobactam } \\
\text { (N/\%) }\end{array}$ & \multicolumn{2}{c}{$\begin{array}{c}\text { Ceftriaxone } \\
(\mathrm{N} / \%)\end{array}$} & \multicolumn{2}{c}{$\begin{array}{c}\text { Ceftazidime } \\
(\mathrm{N} / \%)\end{array}$} & \multicolumn{2}{c}{$\begin{array}{c}\text { Meropenem } \\
(\mathrm{N} / \%)\end{array}$} \\
& $\mathrm{S}$ & $\mathrm{R}$ & $\mathrm{S}$ & $\mathrm{R}$ & $\mathrm{S}$ & $\mathrm{R}$ & $\mathrm{S}$ & $\mathrm{R}$ \\
\hline Pseudomonas spp. & $26(74.28)$ & $9(25.72)$ & $8(22.86)$ & $27(77.24)$ & $2(5.71)$ & $33(94.29)$ & $9(25.71)$ & $26(74.29)$ \\
E.coli & $22(78.57)$ & $6(21.43)$ & $4(14.29)$ & $24(85.71)$ & $5(17.85)$ & $23(82.15)$ & $14(50)$ & $14(50)$ \\
Acinetobacter & $15(62.5)$ & $9(32.5)$ & $10(41.66)$ & $14(58.44)$ & $5(20.83)$ & $19(79.17)$ & $6(25)$ & $18(75)$ \\
Klebsiella spp. & $11(61.11)$ & $7(38.89)$ & $3(16.67)$ & $15(83.33)$ & $10(55.55)$ & $8(44.45)$ & $12(66.67)$ & $6(33.33)$ \\
Staph aureus & $0(00)$ & $0(00)$ & $6(54.55)$ & $5(45.45)$ & $6(54.55)$ & $5(45.45)$ & $10(90.9)$ & $1(9.1)$ \\
Strep. pneumonae & $2(100)$ & $0(00)$ & $2(100)$ & $0(00)$ & $1(50)$ & $1(50)$ & $2(100)$ & $0(00)$ \\
Proteus mirabilis & $0(00)$ & $2(100)$ & $0(00)$ & $2(100)$ & $0(00)$ & $2(100)$ & $0(00)$ & $2(100)$ \\
Morganellamorganii & $1(50)$ & $1(50$ & $1(50)$ & $1(50)$ & $0(00)$ & $2(100)$ & $0(00)$ & $2(100)$ \\
Citrobacter & $0(00)$ & $0(00)$ & $0(00)$ & $2(100)$ & $0(00)$ & $2(100)$ & $0(00)$ & $2(100)$ \\
Enterococcus & $0(00)$ & $0(00)$ & $1(100)$ & $0(00)$ & $0(00)$ & $1(100)$ & $0(00)$ & $1(100)$ \\
\hline
\end{tabular}

$\mathrm{S}=$ Sensitivity, $\mathrm{R}=$ Resistance

Table 5

Distribution of microorganisms according to susceptibility to aminoglycosides. $(N=125)$

\begin{tabular}{|c|c|c|c|c|c|c|}
\hline \multirow[t]{2}{*}{ Microorganisms } & \multicolumn{2}{|c|}{ Amikacin(N/\%) } & \multicolumn{2}{|c|}{ Gentamicin(N/\%) } & \multicolumn{2}{|c|}{ Netilmicin(N/\%) } \\
\hline & $\mathrm{S}$ & $\mathrm{R}$ & $\mathrm{S}$ & $\mathrm{R}$ & $\mathrm{S}$ & $\mathrm{R}$ \\
\hline Pseudomonas spp. & $11(31.43)$ & $24(68.57)$ & $9(25.71)$ & $26(74.29)$ & $19(54.25)$ & $16(45.75)$ \\
\hline E.coli & $8(28.57)$ & $20(71.43)$ & $4(14.29)$ & $24(85.71)$ & $20(71.43)$ & $8(28.57)$ \\
\hline Acinetobacter & $8(33.33)$ & $16(66.67)$ & $6(25)$ & $18(75)$ & $12(50)$ & $12(50)$ \\
\hline Klebsiella spp. & $5(27.78)$ & $13(72.22)$ & $5(27.78)$ & $13(72.28)$ & $11(61.11)$ & $7(38.89)$ \\
\hline Staph aureus & $0(00)$ & $0(00)$ & $6(54.55)$ & $5(45.45)$ & $0(00)$ & $0(00)$ \\
\hline Strep. pneumonae & $1(50)$ & $1(50)$ & $0(00)$ & $2(100)$ & $1(50)$ & $1(50)$ \\
\hline Proteus mirabilis & $0(00)$ & $2(100)$ & $0(00)$ & $2(100)$ & $0(00)$ & $0(00)$ \\
\hline Morganellamorganii & $0(00)$ & $2(100)$ & $0(00)$ & $2(100)$ & $0(00)$ & $2(100)$ \\
\hline Citrobacter & $0(00)$ & $2(100)$ & $0(00)$ & $2(100)$ & $0(00)$ & $2(100)$ \\
\hline Enterococcus & $0(00)$ & $1(100)$ & $0(00)$ & $1(100)$ & $0(00)$ & $1(100)$ \\
\hline
\end{tabular}

$\mathrm{S}=$ Sensitivity, $\mathrm{R}=$ Resistance

Table-VI

Distribution of microorganisms according to susceptibility to quinolones and other antibiotics $(N=125)$

\begin{tabular}{|c|c|c|c|c|c|c|c|c|}
\hline \multirow[t]{2}{*}{ Microorganisms } & \multicolumn{2}{|c|}{ Ciprofloxacin(N/\%) } & \multicolumn{2}{|c|}{ Levofloxacin(N/\%) } & \multicolumn{2}{|c|}{ Colistin(N/\%) } & \multicolumn{2}{|c|}{ Cotrimoxazole(N/\% } \\
\hline & $\mathrm{S}$ & $\mathrm{R}$ & $\mathrm{S}$ & $\mathrm{R}$ & $\mathrm{S}$ & $\mathrm{R}$ & $\mathrm{S}$ & $\mathrm{R}$ \\
\hline Pseudomonas spp. & $8(22.85)$ & $27(77.15)$ & $14(40)$ & $21(60)$ & $20(57.14)$ & $15(42.86)$ & $9(25.71)$ & $26(74.29)$ \\
\hline E.coli & $5(17.86)$ & $23(82.14)$ & $6(21.43)$ & $22(78.57)$ & $0(00)$ & $0(00)$ & $12(42.86)$ & $16(57.14)$ \\
\hline Acinetobacter & $2(8.33)$ & $22(91.67)$ & $5(20.83)$ & $19(79.17)$ & $14(58.33)$ & $8(41.67)$ & $16(66.67)$ & 8(33.33) \\
\hline Klebsiella spp. & $3(16.67)$ & $15(83.33)$ & $5(17.78)$ & 13(82.22) & $0(00)$ & $0(00)$ & $11(61.11)$ & $7(38.89)$ \\
\hline Staph aureus & $4(36.36)$ & $7(63.64)$ & $6(54.54)$ & $5(45.46)$ & $0(00)$ & $0(00)$ & $8(72.72)$ & $3(27.28)$ \\
\hline Strep. pneumonae & $1(50)$ & $1(50)$ & $1(50)$ & $1(500$ & $-0(00)$ & $0(00)$ & $0(00)$ & $\mathrm{O}(00)$ \\
\hline Proteus mirabilis & $0(00)$ & $2(100)$ & $0(00)$ & $2(100)$ & $0(00)$ & $2(100)$ & $0(00)$ & $0(00)$ \\
\hline Citrobacter & $0(00)$ & $2(100)$ & $0(00)$ & $2(100)$ & $0(00)$ & $0(00)$ & $0(00)$ & $0(00)$ \\
\hline Morganellamorganii & $0(00)$ & $2(100)$ & $0(00)$ & $2(100)$ & $1(50)$ & $1(50)$ & $0(00)$ & $0(00)$ \\
\hline Enterococcus & $0(00)$ & $1(100)$ & $0(00)$ & $1(100)$ & $0(00)$ & $0(00)$ & $0(00)$ & $\mathrm{O}(00)$ \\
\hline
\end{tabular}

$\mathrm{S}=$ Sensitivity, $\mathrm{R}=$ Resistance 
Table-VII

Antibiotic resistance pattern of the major organisms isolated from different samples

\begin{tabular}{lc}
\hline Antibiotic & $\begin{array}{c}\text { No./percentage of isolates } \\
\text { showing resistance }\end{array}$ \\
\hline Ciprofloxacin & $102 / 81.6 \%$ \\
Levofloxacin & $88 / 70.4 \%$ \\
Ceftriaxone & $90 / 72 \%$ \\
Ceftazidime & $98 / 78.4 \%$ \\
Amikacin & $81 / 64.8 \%$ \\
Gentamicin & $105 / 84 \%$ \\
Netilmicin & $49 / 39.2 \%$ \\
Meropenem & $62 / 49.6 \%$ \\
\hline
\end{tabular}

\section{Discussion}

This study provides an analysis of epidemiology and microbiology of infections in the ICU patients of DhakaMedical College Hospital. In this study, aspiration pneumonia, and UTI are the predominant infections; these findings are consistent with those of Kumari et al. ${ }^{18}$ In recent years, a rising trend of infection by gram negative organisms and increase in their resistance pattern has been observed. ${ }^{9}$ Theorganisms that have emerged as most problematic for patients within the ICU include Acinetobacter spp., Klebsiella spp., Pseudomonas spp., andEscherichia coli. ${ }^{19}$ In our study, the most frequent microorganisms derived from samples were the gram-negative organisms consisting of Pseudomonas spp. (28\%), Escherichia coli (22.4\%), Acinetobacter spp. (19.2\%), and Klebsiella spp. (14.4\%); these findings correlate with those of a study done in a private hospital in Dhaka. ${ }^{20}$ In recent years, Acinetobacter spp. have emerged as important pathogens of ICUs, most of them being resistant to ampicillin, carbenicillin, cefotaxime, chloramphenicol, and gentamicin. ${ }^{18,21}$ In our study, Acinetobacter spp. was the number one cause of pneumonia based on samples gathered from the tracheal aspirate and shows resistance to ceftriaxone $(58.4 \%)$, ceftazidime $(79.17 \%)$, amikacin $(66.67 \%)$, gentamicin (75\%) and fluoroquinolones (79.17$91.67 \%)$. These findings are consistent with the results of similar studies conducted in India and Bangladesh. 18,20,22In our study,Acinetobacter spp. were resistant to meropenem $(75 \%)$ but sensitive to cotrimoxazole (66.67\%); similar results were found in other study done in Bangladesh $(79.3 \%$ resistance tomeropenem and $60 \%$ sensitivity to cotrimoxazole) $)^{20}$

Gram-negative bacilli are frequently associated with nosocomial infections in ICUs. Data from a multicenter Intensive Care Unit Surveillance Study (ISS) in the
United States demonstrated that Pseudomonas spp. are frequently isolated from ICU samples and they are especially resistance to fluoroquinolones. ${ }^{23}$ The isolates of Pseudomonas spp. in this study were $28 \%$, mostly from tracheal aspirate $(21 \%)$, blood $(8 \%)$ and urine (6\%). In this study, Pseudomonas spp. were resistant to ceftriaxone (77.24\%), ceftazidime (94.29\%), amikacin $(68.57 \%)$, gentamicin $(74.29 \%)$, quinolones (60$77.15 \%)$ and meropenem $(74.29 \%)$, which is closely consistent with other studies. ${ }^{19,20}$

Another commonly seen resistant pathogen among ICU patients is Klebsiella spp. producing extendedspectrum beta lactamases (ESBLs). ${ }^{22}$ Dramatic rise in ESBLs has led to multidrug resistant Escherichia coli and Klebsiella pneumonia making optimal therapy selection difficult. Our isolates of Klebsiella spp. showed high resistance to broad-spectrum cephalosporins (44.45\%-83.33\%) and gentamicin (72.28\%), but sensitive to meropenem (66.67\%). Again, these findings are very similar to those of a recent study carried out in Dhaka (resistance against cephalosporins and gentamicin $82.6 \%-84.6 \%$ and $66.6 \%$, respectively) ${ }^{20}$

In our observation, Escherichia coli was the most frequent pathogen obtained from patients with UTI. This is similar to the findings of previous studies. ${ }^{20,24}$ In the studyby Islam et al, Escherichia coli was fully susceptible to meropenem, but resistant to ceftriaxone. ${ }^{20}$ In our study, Escherichia coli was mostly sensitive to meropenem (50\%) andnetilmicin (71.43\%), but resistant toceftazidime $(82.15 \%)$, ceftriaxone (85.71\%), levofloxacin $(78.57 \%)$ and ciprofloxacin (82.14\%).

Multidrug resistant Pseudomonas, Acinetobacter and Klebsiella species have given new dimensions to the problem of hospital-associated infections. Hope is there that piperacillin-tazobactam combination showed $<40 \%$ resistance against these 3 organisms.The alarming issue is the infection with Acinetobacter spp., where no single antibiotic showed effective sensitivity.

Our study has got some important limitations. The sample size is relatively small, and is a single-centre study. So, the findings may not be generalizable. Anaerobic cultures and cultures suitable for isolating the fastidious organisms were not done. Some antibiotics which are less commonly used but having increasing importance in concurrent patient management might have been omitted from the sensitivity study. Also, the disc diffusion method, not the broth dilution method was used to determine the antibiotic sensitivity, accordingly, information regarding the minimum inhibitory concentration of antibiotics is lacking. 


\section{Conclusion}

Antibiotic resistance is common among the ICU patients. Gram negative organisms constitute a major portion of the antibiotic resistant organisms. Commonly isolated organisms are often resistant to the commonly available antibiotics. When possible, antibiotics selection should be used based on the results of culture and sensitivity testing. For empirical use, third generation cephalosporins or carbapenems (e.g., meropenem) may be the optimal initial choice. Colomycin (colistin) and piperacillintazobactamcombination should be kept preserved for further use. Antibiotic usage guidelines may be formulated according to the resistance pattern in individual institutions. These should be based on further, well-designed studies. Rational use of antibiotic is the key to combat Antimicrobial Resistance.

Conflict of interest: We have no conflict of interest.

\section{References:}

1. Marwick C, Davey P. Care bundles: the holy grail of infectious risk management in hospital? CurrOpin Infect Dis. 2009 Aug;22(4):364-9. https://doi.org/ 10.1097/QCO.0b013e32832e0736. PMid:19506477

2. Hanberger H, Garcia-Rodriguez JA, Gobernado M, Goossens H, Nilsson LE, Struelens MJ. Antibiotic susceptibility among aerobic gram-negative bacilli in intensive care units in 5 European countries. French and Portuguese ICU Study Groups. JAMA. 1999 Jan 6;281(1):67-71. https://doi.org/10.1001/ jama.281.1.67 PMid:9892453

3. Vincent JL, Bihari DJ, Suter PM, Bruining HA, White J, Nicolas-Chanoin MH, Wolff M, Spencer RC, Hemmer $M$. The prevalence of nosocomial infection in intensive care units in Europe. Results of the European Prevalence of Infection in Intensive Care (EPIC) Study. EPIC International Advisory Committee. JAMA. 1995 Aug 23-30;274(8):639-44. https://doi.org/10.1001/ jama.1995.03530080055041.PMid:7637145

4. Vandijck DM, Depaemelaere M, Labeau SO, Depuydt PO, Annemans L, Buyle FM, Oeyen S, Colpaert KE, Peleman RP, Blot SI, Decruyenaere JM. Daily cost of antimicrobial therapy in patients with Intensive Care Unit-acquired, laboratory-confirmed bloodstream infection. Int J Antimicrob Agents. 2008 Feb;31(2):1615. https://doi.org/10.1016/j.ijantimicag.2007.10.015. PMid:18164599

5. Blot S. Limiting the attributable mortality of nosocomial infection and multidrug resistance in intensive care units. Clin Microbiol Infect. 2008 Jan;14(1):5-13. https://doi.org/ $10.1111 /$ j. 1469 0691.2007.01835.x.PMid:17944969

6. Blot S, Depuydt P, Vandewoude K, De Bacquer D. Measuring the impact of multidrug resistance in nosocomial infection. CurrOpin Infect Dis. 2007 Aug;20(4):391-6.https://doi.org/10.1097/ QCO.0b013e32818be6f7.PMid:17609598

7. Vincent JL, Rello J, Marshall J, Silva E, Anzueto A, Martin CD, Moreno R, Lipman J, Gomersall C, Sakr Y, Reinhart K; EPIC II Group of Investigators. International study of the prevalence and outcomes of infection in intensive care units. JAMA. 2009 Dec 2;302(21):23239. doi: 10.1001/jama.2009.1754.

8. Picard KM, O'Donoghue SC, Young-Kershaw DA, Russell KJ. Development and implementation of a multidisciplinary sepsis protocol. Crit Care Nurse. 2006 Jun;26(3):43-54.https: / / doi.org/ 10.4037 / ccn2006.26.3.43.PMid:16717386

9. Carlet J, Ben Ali A, Tabah A, Willems V, Philippart F, Chafine A, Garrouste- Orgeas M, Misset B: Multidrug resistant infections in the ICU: mechanisms, prevention and treatment. In 25 Years of Progress and Innovation in Intensive Care Medicine. Edited by: Kuhlen R, Moreno R, Ranieri VM, Rhodes A. Berlin, Germany: MedizinischWissenschaftlicheVerlagsgesellschaft; 2007:199-211.

10. Salgado CD, O'Grady N, Farr BM. Prevention and control of antimicrobial-resistant infections in intensive care patients. Crit Care Med. 2005 Oct;33(10):237382. doi: 10.1097/01.ccm.0000181727.04501.f3.

11. Cosgrove SE. The relationship between antimicrobial resistance and patient outcomes: mortality, length of hospital stay, and health care costs. Clin Infect Dis. 2006 Jan 15;42 Suppl 2:S82-9. doi: 10.1086/499406.

12. Figueiredo Costa S. Impact of antimicrobial resistance on the treatment and outcome of patients with sepsis. Shock. 2008 Oct;30 Suppl 1:23-9. doi: 10.1097/ SHK.0b013e3181818990.

13. Patwardhan RB, Dhakephalkar PK, Niphadkar KB, Chopade BA. A study on nosocomial pathogens in ICU with special reference to multiresistant Acinetobacter baumanniiharbouring multiple plasmids. Indian J Med Res. 2008 Aug;128(2):178-87.

14. Spencer RC .Predominant pathogens found in the Europian prevalence of infection in Intensive care study. Eur J Clin Microbial Infect Dis 1996; 15:281-5. https:/ /doi.org/ 10.1007/BF01695658.PMid:8781877

15. Boucher HW, Talbot GH, Bradley JS, Edwards JE, Gilbert D, Rice LB, Scheld M, Spellberg B, Bartlett J: Bad bugs, no drugs: no ESKAPE! Anupdate from the Infectious Diseases Society of America. Clin Infect Dis 2009;48:1-12. https://doi.org/10.1086/595011. PMid: 19035777

16. Jones RN: Resistance patterns among nosocomial pathogens: trendsover the past few years. Chest 2001;119:397S-404S.https:// doi.org/10.1378/ chest.119.2_suppl.397S PMid:11171776

17. Kaul S, Brahmadathan K N, Jagannati M, Sudarsanam T D, Pitchamuthu K, Abraham O C, John G. One year 
trends in the gram-negative bacterial antibiotic susceptibility patterns in a medical intensive care unit in South India. Indian J Med Microbiol 2007;25:2305.https://doi.org/10.4103/0255-0857.34764.PMid: 17901640

18. Kumari HB, Nagarathna S, Chandramuki A. Antimicrobial resistance pattern among aerobic gramnegative bacilli of lower respiratory tract specimens of intensive care unit patients in a neurocentre. Indian $\mathrm{J}$ Chest Dis Allied Sci. 2007 Jan-Mar;49(1):19-22.

19. Bayram A, Balci I. Patterns of antimicrobial resistance in a surgical intensive care unit of a university hospital in Turkey. BMC Infect Dis. 2006 Oct 25;6:155. doi: 10.1186/1471-2334-6-155.

20. Islam QT, Siddiqui MMR, Raz F, Asrafuzzaman M, Amin MR. Patterns of antimicrobial resistance among intensive care unit patients of a private medical college hospital in Dhaka. Bangladesh Journal of Medicine 2014; 25: 47-51. https://doi.org/10.3329/ bjmed.v25i2. 25088
21. Seifert H, Baginski R, Schulze A, Pulverer G. Antimicrobial susceptibility of Acinetobacter species. Antimicrob Agents Chemother. 1993 Apr;37(4):750-3. doi: $10.1128 /$ aac.37.4.750.

22. Jamshdi M, Javadpour S, Eftekhari TE, Moradi N, Jomehpour F. Antimicrobial resistance pattern among Intensive Care Unit patients. African Journal of Microbiology Research 2009; 3 (10): 590-594.

23. Friedland I, Gallagher G, King T, Woods GL. Antimicrobial susceptibility patterns in Pseudomonas aeruginosa: data from a multicenter Intensive Care Unit Surveillance Study (ISS) in the United States. J Chemother. 2004 Oct;16(5):437-41. doi: 10.1179/ joc.2004.16.5.437.

24. Islam QT. Antimicrobial resistance: A man made crisis. Journal of Bangladesh College of Physicians and Surgeons, 29(3), 120-125. https://doi.org/10.3329/ jbcps.v29i3.9431. 